\title{
Development and Validation of the Infection Prevention Behavior Scale of Individuals (IPBS-I) for the General Population
}

\author{
Myoung-Lyun Heo' \\ Yang-Min Jang ${ }^{2}$ \\ 'Department of Nursing Science, Jeonju \\ University, Jeonju-si, Jeollabuk-do, South \\ Korea; ${ }^{2}$ Department of Nursing Science, \\ Shinsung University, Dangjin, \\ Chungcheongnam-do, South Korea
}

Correspondence: Yang-Min Jang Department of Nursing Science, Shinsung University, Dangjin, Chungcheongnam-do, South Korea

Tel +82-4I-350-1346

Fax +82-4I-350-1345

Email sellrymin@gmail.com
Purpose: This study aimed to develop a scale for measuring infection prevention behavior of individuals and to verify its validity and reliability for the general population.

Patients and Methods: The scale items were selected using a literature review on the chain of infection and its content validity. There were 297 study participants, all of whom provided informed consent. Data were collected online from September 3 to September 8, 2020, using Google Survey in Korea. The scale's construct validity was verified through exploratory and confirmatory factor analyses, criterion validity was Pearson's Correlation, and reliability was tested using Cronbach's alpha.

Results: Twelve items and three factors were selected after a factor and an exploratory factor analysis of 29 scale items. The three factors were pathogen blocking, transmission blocking, and immunity enhancement. A confirmatory factor analysis validated the model goodness of fit, and the convergent validity and discriminant validity of the scale were verified. The correlation coefficient with a scale for respiratory infection prevention practice was 0.69 , thereby confirming the criterion validity of the scale. The reliability of the final scale (Cronbach's alpha) was 0.86 .

Conclusion: This scale is reflective of the social features of the Korean adult population, and it is easy and concise to be administered to general public, making it useful for subsequent studies on infection prevention.

Keywords: chain of infection, health behavior, primary prevention

\section{Introduction}

Coronavirus disease 2019 (COVID-19) has become a global pandemic. COVID-19 has not been the first advent of an epidemic since the $2000 \mathrm{~s}$, as it has been preceded by severe acute respiratory syndrome, novel influenza, Ebola, and Middle Eastern Respiratory Syndrome (MERS). This indicates that the rate at which novel viruses are occurring is increasing and that these viruses are also demonstrating an increased ability to cause a global pandemic, as in the case of the plague and cholera. $^{1}$

What is most fearful about novel infections is that the infection is transmitted amid a lack of accurate information about the transmission route, prognosis, and treatment. In particular, numerous researches have been conducted and more research efforts are underway to develop therapeutic agents or vaccines for COVID-19; however, the effectiveness of these new developments remains unclear. $^{2}$ 
Thus, the best infection prevention measure as of now is to manage infected individuals based on prompt diagnosis and then quarantine them. ${ }^{3,4}$ Historically, the advent of a novel infection has triggered the development of a new culture and healthcare policies, ${ }^{5}$ and the COVID-19 pandemic has also highlighted the importance of contactless conditions, leading to an array of changes, including restrictions on human and material exchanges among countries and individuals. ${ }^{6}$

Currently, numerous researches are underway in all study disciplines, including healthcare, education, economics, tourism, and architecture, to explore the roles and measures of that respective discipline in the postCOVID-19 era, that is, to adapt to the new normal. ${ }^{6-8}$ Especially the field of public health calls for keen responses to the changes brought upon by COVID-19.

Meanwhile, while individuals with comorbidities such as diabetes mellitus or hypertension, and immunocompromised individuals may experience severe respiratory diseases or even die from the COVID-19 infection, other individuals may remain asymptomatic., ${ }^{9,10}$ Asymptomatic carriers are also a source of infection transmission; hence, preventing interpersonal transmission is highly crucial. ${ }^{11}$ Under such conditions, in addition to its roles in the clinical setting, the field of public health is one of the disciplines responsible for researching about novel infections and educating individuals to help them achieve optimal health by preventing the contraction of such infections in their daily lives. However, while research to promote infection prevention behaviors in daily life requires an instrument to measure these behaviors, the currently available tools for measuring infection prevention behaviors focus only on people in specific occupations, such as healthcare professionals or teachers, ${ }^{12,13}$ individuals on anticancer therapy, or those at high risk for a particular disease, such as sexually transmitted diseases and tuberculosis. ${ }^{14-16}$

While the MERS Prevention Behavior Scale was developed following the 2015 MERS outbreak, ${ }^{17}$ a general tool for measuring infection prevention behaviors is needed, as opposed to a tool for a specific pathogen, in order to allow individuals to block the infection in their daily lives and prevent various infections in the future.

An infection occurs and is transmitted through a chain of infection that consists of six links: "pathogen," including bacteria, viruses, and fungi; "reservoir," an environment in which the pathogen survives and proliferates; "portal of exit," the portal through which the pathogen exists to enter another host; "mode of transmission," namely, airborne, droplet, and contact transmissions; "portal of entry," the portal of entry into the host; and "susceptible host," a host with susceptibility to the pathogen. Prevention of infection is possible by blocking one of the links in this chain of infection. Severing a link in this chain of infection is referred to as "medical asepsis." Although this is primarily performed by healthcare providers and staff in hospitals, this technique is critical in daily life as well in order to prevent potential infections in the future. ${ }^{18}$

With the availability of several guidelines for COVID19 in South Korea and abroad, people's awareness and compliance with infection prevention behaviors are probably at highest level in current times; however, an actual analysis of the same is hindered by the lack of instruments to measure these behaviors. Thus, this study aimed to develop a tool for measuring adults' routine infection prevention behaviors in the context of Korean society. The results of this study are expected to serve as foundational data for understanding and assessing the level of infection prevention behaviors of individuals in Korea.

\section{Materials and Methods Study Design}

This was a methodological study aimed at developing and validating the Infection Prevention Behavior Scale of Individuals [IPBS-I] based on breaking the chain of infection. The study was designed in accordance with the DeVellis guidelines for scale development (determining the components, generating an item pool, determining the format for measurement, testing the validity of the initial item pool, reviewing the items, applying items, evaluating the items, and optimizing the scale). ${ }^{19}$ The process is presented in Figure 1.

\section{Stages of Scale Development} Generating the Initial Item Pool

The initial item pool for the Infection Prevention Behavior Scale of Individuals [IPBS-I] was developed with the six links of the chain of infection (pathogen, reservoir, portal of exit, mode of transmission, portal of entry, and susceptible host) as the conceptual framework, and based on a review of Korean and international literature on the behaviors to break each link. Literature was searched on CINAHL, PubMed, EBSCO, RISS, KISS, DBPIA, and Google Scholar using a combination of key terms including "infection," 


\begin{tabular}{|c|c|c|c|}
\hline \multicolumn{3}{|c|}{ Stage } & Detailed contents \\
\hline \multirow{4}{*}{$\begin{array}{l}\text { Generating } \\
\text { the initial } \\
\text { item pool }\end{array}$} & \multirow{2}{*}{$\begin{array}{l}\text { Instrument } \\
\text { components }\end{array}$} & \multirow[t]{2}{*}{ Literature review } & $\begin{array}{l}\text {.Literature was searched on CINAHL, PubMed, EBSCO, RISS, KISS, DBPIA, and } \\
\text { Google Scholar using a combination of key terms including "infection," "prevention," } \\
\text { and "behavior." }\end{array}$ \\
\hline & & & $\begin{array}{l}\text { reference to the prevention guidelines published by health-related organizations } \\
\text { (KCDC, WHO, CDC). }\end{array}$ \\
\hline & Item preparation & \begin{tabular}{|c|} 
Preliminary Item \\
composition \\
\end{tabular} & Developing and reviewing items: 40 item \\
\hline & $\begin{array}{l}\text { Selection of a } \\
\text { response format }\end{array}$ & Likert scale & 5 point Likert scale \\
\hline \multirow{3}{*}{$\begin{array}{l}\text { Content } \\
\text { validity }\end{array}$} & \multirow{2}{*}{\multicolumn{2}{|c|}{$\begin{array}{l}\text { Content validity test } \\
\text { By an expert }\end{array}$}} & 1st Content validity $(n=9)$ : Delete 10 items, 30 items \\
\hline & & & 2nd Content validity $(\mathrm{n}=3)$ :Delete 1 items, 29 items \\
\hline & \multicolumn{2}{|c|}{ Face validity test } & 3rd Content validity $(n=5):$ No deleted items, 29 items \\
\hline \multirow{5}{*}{$\begin{array}{l}\text { Evaluation of } \\
\text { the scale }\end{array}$} & Applying instrument & Main Survey & Inpatients( $\mathrm{n}=297)$ \\
\hline & \multirow[t]{3}{*}{$\begin{array}{l}\text { Evaluation } \\
\text { of instrument }\end{array}$} & \multirow[t]{2}{*}{ Validity test } & $\begin{array}{l}\text { Construct validity: } \\
\text { - Item analysis }(n=130): \text { Delete } 2 \text { items, } 27 \text { items }(r \geq .30) \\
\text { - Exploratory factor analysis }(n=130): \text { EFA was analyzed } 6 \text { times. } \\
\text { Delete } 15 \text { items, } 3 \text { components, } 12 \text { items } \\
\text { - Confirmatory Factor Analysis }(n=167): \text { Model fit, Convergent, Discriminent }\end{array}$ \\
\hline & & & Criterion validity : Respiratory Infection Prevention Compliance Scale \\
\hline & & Reliability test & Internal consistency reliability \\
\hline & Optimization & \begin{tabular}{|l|l} 
Final Instrument \\
\end{tabular} & Final Instrument confirmation ( 3 components, 12 items) \\
\hline
\end{tabular}

Figure I Instrument Development and Validity process.

"prevention," and "behavior." With reference to the prevention guidelines published by health-related organizations, such as the Korea Centers for Disease Control and Prevention, World Health Organization (WHO), and Centers for Disease Control and Prevention, 40 items were developed. Two researchers reviewed the links of the chain of infection and the contents of the items and identified items that could fall under more than one link. For example, "wearing a face mask" can break the portal of entry and portal of exit links, and "washing hands" can break the pathogen and reservoir links. Hence, to establish discriminant validity, the initial items were classified into three factors: block pathogen, block mode of transmission, and improve host immunity.

Since a Likert scale is generally used to measure attitude, ${ }^{20}$ we adopted a five-point Likert scale for measurement, in which a score of 1 indicated "Strongly disagree," 2 indicated "Disagree," 3 indicated "Neutral," 4 indicated "Agree," and 5 indicated "Strongly agree."

\section{Content Validity Testing}

The content validity of the 40 initial items was tested twice by a panel of experts. In the first round, a panel of experts comprising one infection control nurse, one internal medicine specialist, three emergency medicine specialists, and two fundamentals of nursing professors reviewed the relevance of each item for the purpose of measuring routine infection prevention behaviors on a four-point scale: 1 for "not relevant," 2 for "slightly relevant," 3 for "quite relevant," and 4 for "highly relevant." Experts who marked either 1 or 2 were requested to specify their opinions about a possible revision, and the item-content validity index (I-CVI) was computed based on the items rated as either 3 or 4 . The scale-level content validity index/average (S-CVI/Ave) was 0.91, and the I-CVI ranged from 0.60 1.00. Four items with an I-CVI of below 0.80 were deleted. For the second round of validity testing, two researchers analyzed expert opinions on the remaining 36 items, after which they integrated the duplicate items and reviewed the factors to generate 30 items, with 9 items for blocking the pathogen, 12 items for blocking the mode of transmission, and 9 items for improving host immunity.

The panel of experts for the second round comprised one infection control nurse different from the one who participated in the first round, one emergency medicine specialist, and one fundamentals of nursing professor who also participated in the first round. These three experts tested the validity of the 30 items. The S-CVI/Ave was 0.99 , and the I-CVI ranged from $0.70-1.00$. "When taking off the face mask for a moment, make sure the part that 
touches the nose and mouth remains clean" was the only item with an I-CVI of below 0.80. Although infection control guidelines emphasize that individuals should not touch the front part of a face mask and not reuse a disposable face mask, this item was deleted upon determining that it may confuse the readers amid the current COVID-19 pandemic in which people have been re-using face masks multiple times due to face mask unavailability. $^{18}$

Hence, the scale was finalized with eight items for blocking the pathogen, 12 items for blocking the mode of transmission, and nine items for improving host immunity. To garner potential users' opinions about the usefulness of the tool, difficult vocabulary, and unclear items, a face validity was conducted on five people, one from each of the following age groups: $20 \mathrm{~s}, 30 \mathrm{~s}, 40 \mathrm{~s}, 50 \mathrm{~s}$, and $\geq$ $60 \mathrm{~s}$. The results showed that none of the items were difficult to understand, and the survey took less than 10 minutes to complete. Hence, all 29 items were retained in the finalized scale.

\section{Evaluation of the Scale Participants and Data Collection}

This study was conducted on the general population of the Republic of Korea, aged 19 years or older, and capable of autonomously providing informed consent to participate. Underaged minors and individuals incapable of autonomously providing informed consent were excluded. The participants were recruited from September 8 to September 13, 2020, after obtaining approval from the institutional review board. Participant recruitment was performed via social media (eg, Naver BAND, KakaoTalk) using the Google Survey. Based on Hair et al's study, ${ }^{21}$ a sample of 100 or larger and a sample of 100-150 are needed for exploratory factor analysis (EFA) and confirmatory factor analysis (CFA), respectively. Thus, to obtain reliable factors for the scale, data were collected from 300 participants in consideration of potential withdrawals. After excluding three participants who provided careless responses, data from 297 participants were used in the final analysis.

\section{Instrument: Respiratory Infection Prevention Compliance Scale}

The Respiratory Infection Prevention Compliance Scale was developed by Kim for long-term care facility staff. ${ }^{22}$ It is a 12-item tool assessing hand hygiene, flu vaccination, quarantine precautions, and health management, with each item rated on a four-point Likert scale. This tool was tested on middle-aged adults with a mean age of 43.6 years, and the Cronbach's $\alpha$ of the scale was 0.80 at the time of development. The Cronbach's $\alpha$ was 0.82 in a study on college students ${ }^{23}$ and 0.85 in a study on older adults. ${ }^{24}$ Due to the current widespread use of this tool, its wellestablished validity among several age groups, and a lack of Korean instruments for assessing infection prevention behaviors among the general public, this tool was used to test the criterion validity of the Infection Prevention Behavior Scale of Individuals [IPBS-I] developed in this study. The tool was used after obtaining permission from its developer via email, and the Cronbach's $\alpha$ of the scale in this study was 0.76 .

\section{Data Analysis: Validity and Reliability Testing}

The collected data were analyzed using SPSS 25.0 and AMOS 21.0 software. Participants' demographic data were analyzed using frequency analysis and descriptive statistics, and construct validity was tested using EFA and CFA. First, item analysis was performed to examine the mean and standard deviation for each item, and skewness $(<2)$ and kurtosis $(<7)$ were analyzed against West's criteria. ${ }^{25}$ Items that did not meet the cutoff were deleted, and the corrected item-total correlation coefficient was examined against Tabachnick's criteria, ${ }^{26}$ based on which items with a coefficient of 0.30 or lower were deleted. To examine the suitability of the data for EFA, they were analyzed using the Kaiser-Mayer-Olkin (KMO) parameter $(>0.05)$ and Bartlett's test of sphericity $(p<0.05)$. When suitable, principal component analysis was performed using varimax rotation with the number of factors set to three. ${ }^{27}$ The items and number of factors were determined based on cutoffs of 0.40 or higher for communality, 0.40 or higher for factor loading, and $60 \%$ or higher for cumulative variance. CFA was performed on the established factor, and model fit was tested using $\chi^{2}$, df, root mean square residual (RMR), root mean square error of approximation (RMSEA), and standard root mean square residual (SRMR). Convergent validity, which indicates the level of agreement of items that explain a factor, was tested based on $\beta>0.50$, Average Variance Extracted (AVE) $>0.50$, and Construct Reliability $(\mathrm{CR})>0.70$. Furthermore, discriminant validity between the factors was tested based on AVE $>r^{2}$ and $(r \pm 2 *$ Standard error $[\mathrm{SE}]) \neq 1 .{ }^{28}$ The internal consistency of the scale was assessed based on a Cronbach's $\alpha$ of 0.60 or higher, and criterion validity was established by examining whether the correlation 
coefficient ( $\mathrm{r}$ ) of the developed scale with the Respiratory Infection Prevention Compliance Scale is within the range of $0.40-0.80$.

\section{Ethical Considerations}

This study was approved by the Jeonju University institutional review board (JJIRB-200817-HR-2020-0813). The participants signed an informed consent form after reading an information sheet containing details about the purpose, procedure, and method of the study; time required to complete the survey; benefits and risks of study participation; compensation for participation; handling of personal information; and withdrawal from the study. The collected data did not include personally identifiable information, and all data were coded and used only for research purposes.

\section{Results}

\section{Participant Characteristics}

A total of 297 participants were enrolled, their characteristics were analyzed by items such as Age (years), Sex, Religion, Housemate, Education, Occupation, Multiple unspecified contacts, Current disease, Health status, Recognition of the need to prevent infection, and the contents are shown in Table 1.

\section{Item Analysis}

Item analysis was performed using the data of 130 randomly chosen participants. The mean, standard deviation, skewness, and kurtosis were analyzed for 29 initial items. All items had a skewness of below 2, with a range of $-2.14 \sim 0.29$ and a kurtosis of below 7, with a range of $-1.23 \sim 3.96$, confirming normality. To test the internal consistency of the 29 selected items, the correlations between each item and the total score were analyzed; these correlations ranged from $r=0.24 \sim 0.67$. Items 26 and 27 with an $r \leq 3.0$ were deleted. After deleting these two items, the correlations between each item and the total score ranged from $r=0.36 \sim 0.67$ (Table 2).

\section{Exploratory Factor Analysis}

Six rounds of EFA were performed on the remaining 27 items based on item analysis to test the construct validity. EFA was performed using principal component analysis with varimax rotation, and the number of factors was set to three. Items with a communality of below 0.40 or factor loading of 0.50 or lower, and items that applied to more than one factor were deleted after review. As a result, 7 items $(\# 3,10,12,15,19,19,20)$ in round 1,1 item (\#9) in round 2, 1 item in round $3(\# 16), 1$ item in round $4(\# 29)$, and 5 items in round $5(\# 1,2,4,21,28)$ were deleted. Thus, 12 items under three factors were selected. The factors were named "blocking the pathogen," "blocking transmission," and "improving immunity." The KMO value of the 12 items was 0.83 , and Bartlett's test of sphericity indicated a $\chi^{2}=598.93$, and $p<0.001$, with a cumulative of $61.36 \%$. Communality ranged from $0.50 \sim 0.71$, and factor loadings ranged from $0.63 \sim 0.78$ (Table 3).

\section{Confirmatory Factor Analysis}

After excluding the participant data used for EFA, data from the remaining 167 participants were analyzed via CFA. Model fit indices were: $\chi^{2}=100.30(p<0.001)$, $\chi^{2} / \mathrm{df}=1.97, \mathrm{RMR}=0.04, \mathrm{RMSEA}=0.08, \mathrm{SRMR}=0.04$, GFI $=0.91(>0.90)$, CFI $=0.93(>0.90)$, and TuckerLewis Index $(\mathrm{TLI})=0.91(>0.90)$, thereby confirming a good fit (Table 4).

\section{Convergent Validity}

Convergent validity was tested for each item, and the results ranged from $\beta=0.55-0.82$, meeting the criterion of $\beta \geqq 0.50$. AVE was 0.57 for "blocking the pathogen," 0.61 for "blocking transmission," and 0.54 for "improving immunity," thereby meeting the criterion of AVE $>0.50$. CR was 0.84 for "blocking the pathogen," 0.86 for "blocking transmission," and 0.77 for "improving immunity," thereby meeting the criterion of $\mathrm{CR}>0.70$.

\section{Discriminant Validity}

In the first round of discriminant validity testing, $\mathrm{r}^{2}$ for "blocking the pathogen" and "blocking transmission" was 0.567, which was smaller than the AVE values of "blocking the pathogen" (0.57) and "blocking transmission" $(0.61) ; r^{2}$ for "blocking transmission" and "improving immunity" was 0.40 , which was smaller than the AVE values of "blocking transmission" (0.61) and "improving immunity" (0.54); and $\mathrm{r}^{2}$ for "blocking the pathogen" and "improving immunity" was 0.40 , which was smaller than the AVE values of "blocking the pathogen" $(0.57)$ and "improving immunity" (0.54). These results established the discriminant validity of the scale. In the second round of discriminant validity testing, the $(\mathrm{r} \pm 2 * \mathrm{SE}) \neq$ 1 value ranged from $0.65 \sim 0.86$ for "blocking the pathogen" and "blocking transmission," $0.56 \sim 0.71$ for "blocking transmission" and "improving immunity," and 0.53 0.73 
Table I Infection Prevention Behavior, According to the Characteristics of Participants

\begin{tabular}{|c|c|c|c|c|c|c|c|}
\hline & \multirow[t]{2}{*}{ Category } & \multirow{2}{*}{$\begin{array}{c}\text { EFA } \\
(n=130)\end{array}$} & \multirow{2}{*}{$\begin{array}{c}\text { CFA } \\
(n=167)\end{array}$} & \multirow{2}{*}{$\begin{array}{c}\begin{array}{c}\text { Total } \\
(\mathbf{N}=297)\end{array} \\
n(\%)\end{array}$} & \multicolumn{3}{|c|}{$\begin{array}{l}\text { Infection Prevention Behavior } \\
\qquad(N=297)\end{array}$} \\
\hline & & & & & $M \pm S D$ & t or $F$ & $p$ \\
\hline \multirow[t]{5}{*}{ Age (years) } & $19-29^{\mathrm{a}}$ & $25(19.2)$ & $25(15.0)$ & $58(19.5)$ & $3.66 \pm 0.49$ & \multirow{5}{*}{$4.63(\mathrm{a}<\mathrm{b})$} & \multirow{5}{*}{$<0.001$} \\
\hline & $30-39^{b}$ & $53(40.8)$ & $63(37.7)$ & $107(36.0)$ & $3.80 \pm 0.56$ & & \\
\hline & $40-49^{b}$ & $15(11.5)$ & $27(16.2)$ & $44(14.8)$ & $3.77 \pm 0.51$ & & \\
\hline & $50-59^{b}$ & $23(17.7)$ & $35(21.0)$ & $54(18.2)$ & $3.99 \pm 0.45$ & & \\
\hline & $\geqq 60^{\mathrm{b}}$ & $14(10.8)$ & $17(10.2)$ & $34(11.4)$ & $4.04 \pm 0.42$ & & \\
\hline \multirow[t]{2}{*}{ Sex } & Female & $77(59.2)$ & $98(58.7)$ & $174(58.6)$ & $3.92 \pm 0.48$ & \multirow{2}{*}{3.84} & \multirow{2}{*}{$<0.001$} \\
\hline & Male & $53(40.8)$ & $69(41.3)$ & $123(4 \mid .4)$ & $3.70 \pm 0.55$ & & \\
\hline \multirow[t]{2}{*}{ Religion } & Yes & $61(46.9)$ & 81 (48.5) & |4| (47.5) & $3.90 \pm 0.49$ & \multirow{2}{*}{2.39} & \multirow{2}{*}{0.02} \\
\hline & No & $69(53.1)$ & $86(51.5)$ & $156(52.5)$ & $3.76 \pm 0.54$ & & \\
\hline \multirow[t]{2}{*}{ Housemate } & Yes & $107(82.3)$ & $136(8 \mid .4)$ & $253(85.2)$ & $3.86 \pm 0.53$ & \multirow{2}{*}{2.09} & \multirow{2}{*}{0.04} \\
\hline & No & $23(17.7)$ & $31(18.6)$ & $44(14.8)$ & $3.68 \pm 0.41$ & & \\
\hline \multirow[t]{4}{*}{ Education } & $\begin{array}{l}\text { Below high school } \\
\text { graduation }\end{array}$ & $16(12.3)$ & $28(16.8)$ & 59 (19.9) & $3.87 \pm 0.47$ & \multirow[t]{4}{*}{2.14} & \multirow[t]{4}{*}{0.12} \\
\hline & A university student or & $98(75.4)$ & $112(67.1)$ & $194(65.3)$ & $3.79 \pm 0.53$ & & \\
\hline & Graduate school or & $16(12.3)$ & $27(16.2)$ & $44(14.8)$ & $3.96 \pm 0.51$ & & \\
\hline & higher & & & & & & \\
\hline \multirow[t]{4}{*}{ Occupation } & Yes & $92(70.8)$ & $124(74.3)$ & $219(73.7)$ & $3.80 \pm 0.55$ & \multirow[t]{4}{*}{3.88} & \multirow[t]{4}{*}{0.01} \\
\hline & No & $2(1.5)$ & $2(1.2)$ & $4(1.3)$ & $3.88 \pm 0.39$ & & \\
\hline & Student & $9(6.9)$ & II (6.6) & $22(7.4)$ & $3.65 \pm 0.39$ & & \\
\hline & Housewife & $27(20.8)$ & $30(18.0)$ & $52(17.5)$ & $4.03 \pm 0.36$ & & \\
\hline \multirow[t]{2}{*}{ Multiple unspecified contacts } & Yes & $56(43.1)$ & $73(43.7)$ & $132(44.4)$ & $3.79 \pm 0.57$ & \multirow{2}{*}{-1.20} & \multirow{2}{*}{0.23} \\
\hline & No & $74(56.9)$ & $94(56.3)$ & $165(55.6)$ & $3.86 \pm 0.47$ & & \\
\hline \multirow[t]{2}{*}{ Current disease } & Yes & $21(16.2)$ & $24(14.4)$ & $47(15.8)$ & $3.90 \pm 0.47$ & \multirow[t]{2}{*}{1.11} & \multirow[t]{2}{*}{0.27} \\
\hline & No & $109(83.8)$ & $143(85.6)$ & $250(84.2)$ & $3.82 \pm 0.53$ & & \\
\hline \multirow[t]{3}{*}{ Health status } & Not good ${ }^{a}$ & $20(15.4)$ & $16(9.6)$ & $32(10.8)$ & $3.71 \pm 0.59$ & & \\
\hline & Moderate $^{b}$ & $70(53.8)$ & $98(58.7)$ & $166(55.9)$ & $3.79 \pm 0.49$ & $3.80(\mathrm{a}<\mathrm{b})$ & 0.02 \\
\hline & Good $^{b}$ & $40(30.8)$ & $53(31.7)$ & $99(33.3)$ & $3.94 \pm 0.52$ & & \\
\hline Recognition of the need to & Needlessness & $9(6.9)$ & II (6.6) & $21(7.1)$ & $3.92 \pm 0.58$ & & \\
\hline prevent infection & Moderate & $22(16.9)$ & $26(15.6)$ & $46(15.5)$ & $3.75 \pm 0.47$ & 0.84 & 0.43 \\
\hline & Need & $99(76.2)$ & I 30 (77.8) & $230(77.4)$ & $3.84 \pm 0.52$ & & \\
\hline
\end{tabular}

Note: Post-hoc analysis was done by scheffe test, and "a, b" are notation for group classification. Abbreviation: SD, standard deviation.

for "blocking the pathogen" and "improving immunity," based on which discriminant validity among the three factors was established.

\section{Criterion Validity}

To test the criterion validity against the Respiratory Infection Prevention Compliance Scale, correlation analysis was performed using the data from the entire sample $(\mathrm{n}=296)$, and the appropriate correlation between the two instruments was confirmed to be $0.40-0.80$. The correlation between the total scores was $0.69(p<0.001)$, indicating a positive correlation. There was also a positive correlation between the total score of the criterion scale and the three factors of "blocking the pathogen" ( $\mathrm{r}=0.60, p<0.001)$, "blocking transmission" $(\mathrm{r}=0.55, p<0.001)$, and "improving immunity" ( $\mathrm{r}=0.54, p<0.001)$, thereby confirming criterion validity (Table 5). 


\begin{tabular}{|c|c|}
\hline 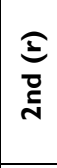 & 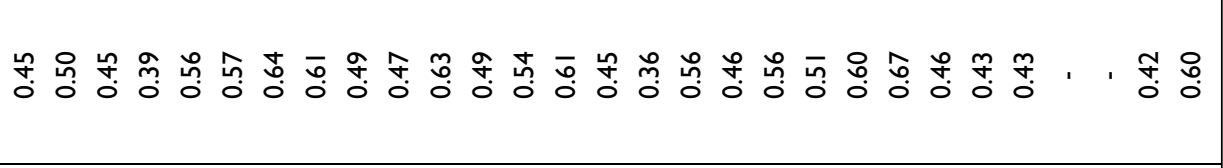 \\
\hline 至 & 告织 旁 \\
\hline & $\bar{i}$ দᄁ \\
\hline & 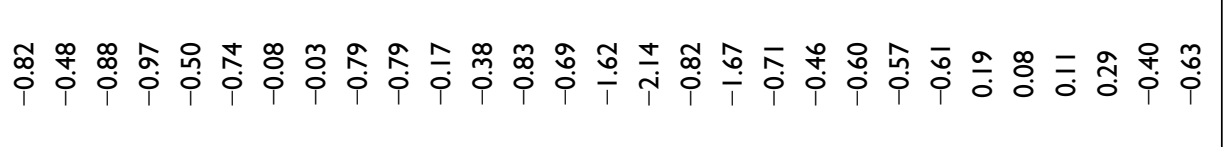 \\
\hline & 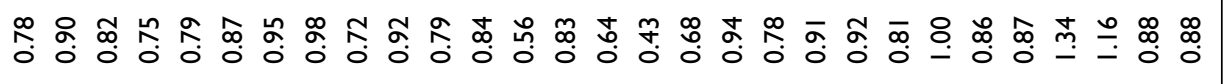 \\
\hline & 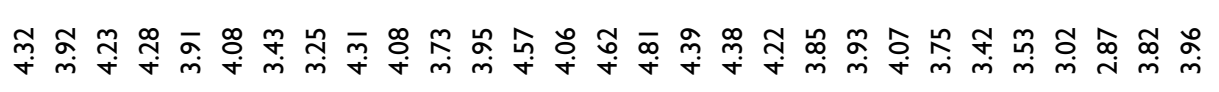 \\
\hline & 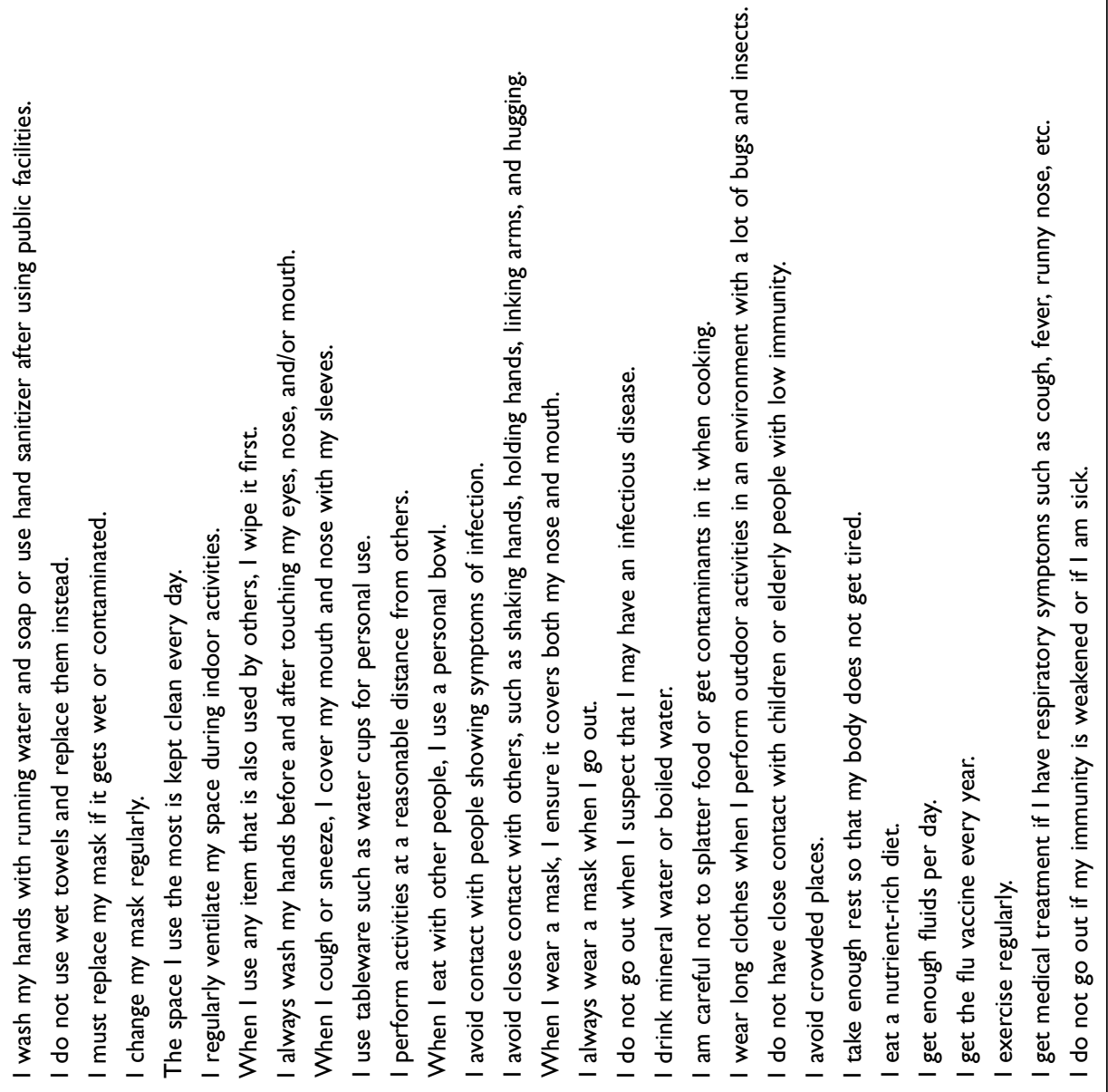 \\
\hline & జ్ల \\
\hline
\end{tabular}


Table 3 Exploratory Factor Analysis $(n=130)$

\begin{tabular}{|c|c|c|c|c|c|}
\hline \multicolumn{2}{|c|}{ Item } & \multicolumn{3}{|c|}{ Factor Loading } & \multirow{3}{*}{$\begin{array}{c}\text { Communality } \\
0.67\end{array}$} \\
\hline & & \multirow{2}{*}{$\begin{array}{c}\text { I } \\
0.78\end{array}$} & \multirow{2}{*}{$\begin{array}{c}\mathbf{2} \\
0.25\end{array}$} & \multirow{2}{*}{$\begin{array}{c}3 \\
-0.07\end{array}$} & \\
\hline 13 & I avoid contact with people showing symptoms of infection. & & & & \\
\hline 14 & I avoid close contact with others, such as shaking hands, holding hands, linking arms, and hugging. & 0.70 & 0.15 & 0.32 & 0.61 \\
\hline II & I perform activities at a reasonable distance from others. & 0.67 & 0.21 & 0.30 & 0.58 \\
\hline 17 & I do not go out when I suspect that I may have an infectious disease. & 0.67 & 0.21 & 0.10 & 0.50 \\
\hline 22 & I avoid crowded places. & 0.65 & 0.32 & 0.23 & 0.59 \\
\hline 5 & The space I use the most is kept clean every day. & 0.33 & 0.77 & -0.01 & 0.71 \\
\hline 8 & I always wash my hands before and after touching my eyes, nose, and/or mouth. & 0.17 & 0.71 & 0.31 & 0.63 \\
\hline 7 & When I use any item that is also used by others, I wipe it first. & 0.19 & 0.69 & 0.35 & 0.63 \\
\hline 6 & I regularly ventilate my space during indoor activities. & 0.40 & 0.63 & 0.03 & 0.56 \\
\hline 23 & I take enough rest so that my body does not get tired. & 0.31 & -0.05 & 0.76 & 0.68 \\
\hline 24 & I eat a nutrient-rich diet. & 0.20 & 0.19 & 0.75 & 0.64 \\
\hline 25 & I get enough fluids per day. & -0.03 & 0.34 & 0.66 & 0.56 \\
\hline
\end{tabular}

Notes: Kaiser-Meyer-Olkin values $=0.83$, Bartlett's sphericity test: $\chi^{2}=598.93 p<0.001$, Total explanatory power $=61.36 \%$.

Table 4 Confirmatory Factor Analysis $(n=167)$

\begin{tabular}{|c|c|c|c|c|c|c|c|c|c|}
\hline \multirow[t]{3}{*}{ Variable } & \multirow[t]{3}{*}{ Item } & \multirow{3}{*}{$\begin{array}{c}\text { Standardized } \\
\text { Estimate }(\beta) \\
(\geq 0.5)\end{array}$} & \multirow{3}{*}{$\begin{array}{c}\text { Error } \\
\text { variances }\end{array}$} & \multirow[t]{3}{*}{$\operatorname{AVE}(\geq 0.5)$} & \multirow[t]{3}{*}{$C R(\geq 0.7)$} & \multicolumn{4}{|c|}{ Correlation } \\
\hline & & & & & & \multicolumn{2}{|c|}{$\begin{array}{l}\text { Pathogen } \\
\text { Blocking }\end{array}$} & \multicolumn{2}{|c|}{$\begin{array}{c}\text { Transmissior } \\
\text { Blocking }\end{array}$} \\
\hline & & & & & & $\mathbf{r}$ & SE & $\mathbf{r}$ & SE \\
\hline \multirow[t]{4}{*}{ Pathogen blocking } & 8 & 0.72 & 0.47 & \multirow{4}{*}{0.57} & \multirow{4}{*}{0.84} & \multirow{4}{*}{1.00} & & & \\
\hline & 7 & 0.67 & 0.54 & & & & & & \\
\hline & 6 & 0.71 & 0.34 & & & & & & \\
\hline & 5 & 0.82 & 0.24 & & & & & & \\
\hline \multirow[t]{5}{*}{ Transmission blocking } & 22 & 0.64 & 0.39 & \multirow{5}{*}{0.61} & \multirow{5}{*}{0.86} & \multirow{5}{*}{0.75} & \multirow{5}{*}{0.05} & \multirow{5}{*}{1.00} & \\
\hline & 17 & 0.61 & 0.29 & & & & & & \\
\hline & 14 & 0.76 & 0.30 & & & & & & \\
\hline & 13 & 0.65 & 0.19 & & & & & & \\
\hline & 11 & 0.72 & 0.34 & & & & & & \\
\hline \multirow{3}{*}{$\begin{array}{l}\text { Immunity } \\
\text { enhancement }\end{array}$} & 25 & 0.58 & 0.45 & \multirow{3}{*}{0.54} & \multirow{3}{*}{0.77} & \multirow{3}{*}{0.63} & \multirow{3}{*}{0.05} & \multirow{3}{*}{0.64} & \multirow{3}{*}{0.04} \\
\hline & 24 & 0.81 & 0.24 & & & & & & \\
\hline & 23 & 0.55 & 0.45 & & & & & & \\
\hline
\end{tabular}

Notes: Model fitness: $\chi^{2}=100.30(p<0.00 \mathrm{I}), \chi^{2} / \mathrm{df}=1.97(\leqq 3), \mathrm{RMR}=0.04(\leqq 0.05), \mathrm{RMSEA}=0.08(\leqq 0.10), \mathrm{SRMR}=0.04(\leqq 0.05), \mathrm{GFI}=0.91(\geqq 0.90), \mathrm{CFI}=0.93$ $(\geqq 0.90), \mathrm{TLI}=0.91(\geqq 0.90)$.

Abbreviations: SE, standard error; AVE, average variance extracted; CR, construct reliability; RMR, root mean square residual; RMSEA, root mean square error of approximation; SRMR, standard root mean square residual; GFI, goodness-of-fit index; CFI, comparative fit index; TLI, Tucker-Lewis index. 
Table 5 The Reliability and Criterion Validity of the Infection Prevention Behavior Scale of Individuals [IPBS-I] (N = 297)

\begin{tabular}{|l|c|c|c|c|c|}
\hline Dimension & M & SD & Cronbach's $\alpha$ & \multicolumn{2}{|c|}{ Respiratory Infection Prevention Practice } \\
\cline { 3 - 5 } & & & & $\mathbf{r}$ & $\mathbf{P}$ \\
\hline Total (12) & 3.83 & 0.52 & 0.86 & 0.69 & $<0.001$ \\
Pathogen blocking (4) & 3.65 & 0.71 & 0.79 & 0.60 & $<0.001$ \\
Transmission blocking (5) & 4.13 & 0.56 & 0.80 & 0.55 & $<0.001$ \\
Immunity enhancement (3) & 3.58 & 0.66 & 0.67 & 0.54 & $<$ \\
\hline
\end{tabular}

\section{Reliability}

The mean score for the Infection Prevention Behavior Scale of Individuals [IPBS-I] developed in this study was $3.83 \pm 0.57$, with a mean score of $3.65 \pm 0.71$ for "blocking the pathogen," $4.13 \pm 0.56$ for "blocking transmission," and $3.58 \pm 0.66$ for "improving immunity." The reliability of the entire scale (Cronbach's $\alpha$ ) was 0.86 , with a Cronbach's $\alpha$ of 0.79 for "blocking the pathogen," 0.80 for "blocking transmission," and 0.67 for "improving immunity" (Table 5).

\section{Infection Prevention Behaviors According to Participant Characteristics}

The 12-item Infection Prevention Behavior Scale of Individuals [IPBS-I] was analyzed according to participant characteristics. The scores differed significantly according to age $(\mathrm{F}=4.63, p<0.001)$, sex $(\mathrm{t}=3.84, p<0.001)$, religion $(\mathrm{t}=2.39, p=0.02)$, cohabitant $(\mathrm{t}=2.09, p=0.04)$, occupation $(\mathrm{F}=3.88, p=0.01)$, and perceived health status $(\mathrm{F}=3.80, p=0.02)($ Table 1$)$.

\section{Discussion}

The Infection Prevention Behavior Scale of Individuals [IPBS-I] developed in this study is a 12-item scale consisting of the three factors of "blocking the pathogen," "blocking transmission," and "improving immunity." Here, we first discuss the scale validation process and the results.

In the expert validity testing of the initial item pool, items with a CVI of 0.80 or higher were primarily chosen, and there were some disagreements about the items for "improving immunity." The last link of the chain of infection is a susceptible host, so acquiring an infection may depend on an individual's health. ${ }^{18}$ In general, regular diet $^{29}$ regular exercise, ${ }^{30}$ and adequate water intake ${ }^{31}$ are known to be essential to improve immunity. However, during the validity testing, some experts stated that these behaviors are only weakly associated with infection prevention, and some stated that regular exercise indoors may actually increase the risk of exposure. Based on these opinions, "I eat regularly" and "I exercise regularly" were deleted. However, items "I take good rest so I will not feel tired," "I eat nutritious meals," and "I drink enough water every day" were included in the item analysis and EFA process, showing that these items are appropriate for measuring infection prevention behaviors.

As the purpose of this scale is to measure overall infection prevention behaviors in daily life, items such as "I wear long sleeves and long pants when going outdoors inhabited by various insects," "I try not to contaminate my food with saliva or other things when cooking," and "I drink only filtered water or boiled water" were selected for analysis in consideration of the various means of transmission. However, these items did not meet the cutoff in the EFA and were deleted. The current promotion of COVID19 prevention guidelines in multiple forums and good compliance by the general public could have resulted in the items related to social distancing correlating highly and clustering around the blocking transmission factor, and behaviors perceived to be less relevant to COVID-19 not clustering as a common factor. In the future, novel infections mediated by mosquitos or insects are anticipated to occur as a result of climate change, ${ }^{32}$ highlighting the need for an infection prevention behavior scale with items related to vector transmission.

In the CFA, the $\chi^{2}$ was $100.30(p<0.001)$ and did not meet the cutoff; however, as the criterion of $\chi^{2}$ has tended to be excluded in recent years due to its high sensitivity to sample size and strict criterion, ${ }^{33}$ model fit was established based on the absolute fit indices of RMR, RMSEA, and SRMR. Furthermore, among the normed fit indices, both TLI, which is relatively insensitive to sample size and is a good representation of model parsimony, and CFI, which is widely used owing to its low sensitivity to model complexity, satisfied the criteria, further confirming the model fit. ${ }^{28,33}$ In particular, the 
present scale satisfied the convergent validity and discriminant validity criteria, indicating that each item consistently measures its respective factor and that the factors are mutually independent. As previously mentioned, breaking the chain of infection is limited in terms of redundancy among the links, but one strength of this scale is that a good distinction among its constructs could be established.

Many past studies have used split-half reliability to test the reliability of a scale, but internal consistency reliability has been recommended in recent years, as it computes all possible split-half reliabilities and presents it as a single Cronbach's $\alpha$ coefficient. $^{34}$ The Cronbach's $\alpha$ of the scale developed in this study was 0.86 , indicating good reliability, with a coefficient of 0.79 for "blocking the pathogen," 0.80 for "blocking transmission," and 0.67 for "improving immunity," confirming internal consistency. The Cronbach's $\alpha$ for "improving immunity," although below 0.70 , can be deemed appropriate with reference to a previous finding that the Cronbach's $\alpha$ of the subscales of a developed tool ranges from $0.60-0.69 .^{34}$ Subsequently, studies should continue to investigate a more diverse sample to improve the reliability of the tool.

Finally, a correlation coefficient of 0.69 with the existing Respiratory Infection Prevention Compliance Scale established the developed scale's criterion validity. A correlation of 0.80 or higher may actually indicate that the two scales measure the same construct; ${ }^{35}$ hence, a correlation of 0.69 is considered appropriate.

The finalized tool was assessed and the mean total score of routine infection prevention behaviors was moderate at $3.83 \pm$ 0.52 , with a mean score of $3.65 \pm 0.71$ for "blocking the pathogen," $4.13 \pm 0.66$ for "blocking transmission," and 3.58 \pm 0.66 for "improving immunity." The mean score was the highest for "blocking transmission," presumably because this factor contained items mostly about social distancing, which is currently a measure enforced nationwide. ${ }^{36,37}$ The score for "improving immunity" was the lowest, calling for the implementation of relevant guidelines or programs to fundamentally prevent infection.

In terms of the participants' general characteristics, routine infection prevention behaviors significantly differed according to age, sex, religion, cohabitant, occupation, and health status. In particular, there are growing concerns about the transmission of COVID-19 by young adults in their $20 \mathrm{~s}$, and our results showed that people in their 20s engage in significantly fewer infection prevention behaviors compared to those in other age groups. In addition, students also showed the lowest infection prevention behavior score compared to those in other occupations. This may be contextually in line with the findings of a previous study, ${ }^{38}$ which indicated that young adults in their 20s show lower compliance with health management behaviors compared to those in other age groups because of their belief that they will be healthier; thus, continued research to develop measures to promote infection prevention behaviors among young adults is warranted.

Participants who reported following a religion showed a higher infection prevention behavior score than those not following any religion. This may be attributable to the fact that people following a religion strive to reduce the spread of the infection to their family and the society from their group-based religious activities, which triggered several cases of COVID19 in Korea. ${ }^{39}$ Furthermore, people aged 60 or older demonstrated better compliance with infection prevention behaviors in their daily lives compared to other age groups, possibly to prevent spreading the infection to their children or grandchildren. However, research data on this matter remains thin; therefore, further studies are needed to identify various factors that promote infection prevention behaviors with reference to our findings.

The final scale developed in this study comprised 12 items. With such brevity and the established reliability and validity of the scale on the general public, it is appropriate for measuring infection prevention behaviors. Furthermore, it can be useful as foundational data for determining the direction of policies to promote infection prevention behaviors and for developing relevant education programs. Therefore, we hope that subsequent studies will continue to study the scale to provide a framework for preventing various infectious diseases that may affect our daily lives.

Despite the scope covered by this study, the study still has some limitations. First, the data in this study were collected only from a specific sample in Korea and this study used the minimum number of samples suitable for factor analysis.; hence, subsequent studies should utilize a broader sample to ensure the generalizability of the findings. Second, although this study is to develop a general infection prevention behavior measurement tool. But caution should be exercised when using the results of this study, because the awareness level of infection prevention due to the COVID-19 was high at the time this study was conducted. Third, while predictive validity of the respiratory infection prevention behavior was confirmed in this study, the predictive validity according to the propagation route of droplets and contact was not confirmed. Additional research is therefore needed on this topic. 


\section{Conclusions}

This study developed a scale for measuring the infection prevention behaviors of individuals in an environment with potential exposure to various infections. The finalized scale consists of 12 items under three factors (blocking the pathogen, blocking transmission, and improving immunity), and the reliability and validity of the scale have been verified. This scale is reflective of the social features of the Korean adult population, and it is easy and concise to be administered to general public, making it useful for subsequent studies on infection prevention. Therefore, the measurement of personal infection prevention behavior through this tool will contribute to providing basic data for future infectious disease prevention.

\section{Abbreviations}

$\mathrm{CR}$, construct reliability; I-CVI, item-content validity index; IPBS-I, Infection Prevention Behavior Scale of Individuals; KMO, Kaiser-Mayer-Olkin; RMR, root mean square residual; RMSEA, root mean square error of approximation; S-CVI, scale-level content validity index; SRMR, standard root mean square residual; WHO, World Health Organization.

\section{Ethics Approval and Consent to Participate}

The study was conducted according to the guidelines of the Declaration of Helsinki, and approved by the Jeonju University institutional review board (JJIRB-200817-HR -2020-0813). Informed consent was obtained from all subjects involved in the study

\section{Acknowledgments}

We thank all the participants who participated in the study and the medical staff who checked the validity of the content even in the midst of their busy schedule given the COVID-19 pandemic.

\section{Author Contributions}

All authors made a significant contribution to the work reported, whether that is in the conception, study design, execution, acquisition of data, analysis and interpretation, or in all these areas; took part in drafting, revising or critically reviewing the article; gave final approval of the version to be published; have agreed on the journal to which the article has been submitted; and agree to be accountable for all aspects of the work.

\section{Funding}

This research was supported by the Research Grant of Jeonju University in 2020.

\section{Disclosure}

The authors declare no conflict of interest.

\section{References}

1. Cucinotta D, Vanelli M. WHO declares COVID-19 a pandemic. Acta Biomed. 2020;91(1):157-160. doi:10.23750/abm.v91i1.9397

2. Rothan HA, Byrareddy SN. The epidemiology and pathogenesis of coronavirus disease (COVID-19) outbreak. J Autoimmun. 2020;109:102433. doi:10.1016/j.jaut.2020.102433

3. Pandey S, Yadav B, Pandey A, et al. Lessons from SARS-CoV-2 pandemic: evolution, disease dynamics and future. Biology. 2020;9 (6):141. doi:10.3390/biology9060141

4. Li Y, Tenchov R, Smoot J, et al. A comprehensive review of the global efforts on COVID-19 vaccine development. ACS Cent Sci. 2021;7(4):512-533. doi:10.1021/acscentsci.1c00120

5. Song YG. 전염병의 역사는 '진행 중' [The history of infectious diseases is now 'under way']. Korean J Med. 2005;68:127-129. Korean.

6. Bae YI, Shin HR. Accelerating the corona 19 untact society. Issue \& Analysis. 2020:1-26.

7. Noh JS. Corona and economic democratization. Democr Leg Stud. 2020;73:349-374. doi:10.15756/dls.2020.73.349

8. Oh EG. 포스트코로나 뉴노멀 시대의 간호의 전망과 대책 [Perspectives on nursing profession for a post-COVID-19 new normal]. Korean J Adult Nurs. 2020;32(3):221-222. doi:10.7475/ kjan.2020.32.3.221 Korean.

9. Huang C, Wang Y, Li X, et al. Clinical features of patients infected with 2019 novel coronavirus in Wuhan, China. Lancet. 2020;395 (10223):497-506. https://doi.org/10.1016/S0140-6736(20)30183-5

10. Benjamin GM, Ghazal A, Katya L, et al. Predictors of COVID-19 severity: a literature review. Rev Med Virol. 2021;31(1):1-10. doi:10.1002/rmv.2146

11. Ye F, Xu S, Rong Z, et al. Delivery of infection from asymptomatic carriers of COVID-19 in a familial cluster. Int $J$ Infect Dis. 2020;94:133-138. doi:10.1016/j.ijid.2020.03.042

12. Kim NY, Jeong SY. Perception on and behaviors for blood-borne infection prevention among operating room nurses. $J$ Korean Clin Nurs Res. 2016;22(3):276-284. doi:10.22650/JKCNR.2016.22.3.276

13. Kim JS. Effects of a training program on infection prevention for staff of child daycare centers. Child Health Nurs Res. 2007;13 (4):467-477.

14. Kim JH, Park MK. Study on the knowledge of cervical cancer and human papillomavirus and preventive behavior intention of female university students. J Korean Acad Soc Nurs Edu. 2009;15 (2):225-231. doi:10.5977/JKASNE.2009.15.2.225

15. Lee YR, Kwon IS. The relationship between infection prevention behaviors and barriers among cancer patients undergoing chemotherapy. Asian Oncol Nurs. 2007;7(2):150-161.

16. Im SJ, Lee HJ. The effect of knowledge, attitudes and prevention behaviors for tuberculosis infection in nursing students. $J$ Korean Biol Nurs Sci. 2016;18(1):43-50. doi:10.7586/jkbns.2016.18.1.43

17. Park JH, Jang SJ, Kim KS. Correlation between the preventive behaviors on Middle East respiratory syndrome and the knowledge, attitude, and compliance of medically inclined college students. $J$ Dent Hyg Sci. 2017;17(4):341-351. doi:10.17135/ jdhs.2017.17.4.341

18. Taylor C, Lynn P, Bartlett J. Fundamentals of Nursing: The Art and Science of Person-Centered Care. 2nd ed. New York: Lippincott Williams \& Wilkins; 2018. 
19. DeVellis RF. Scale Development: Theory and Applications. 4th ed. Thousand Oaks: Sage publications; 2016.

20. Kim KM. 리커트 척도 [Likert scale]. Korean J Fam Med. 2011;32 (1):1-2. doi:10.4082/kjfm.2011.32.1.1. Korean.

21. Hair JF, Black WC, Babin BJ, Anderson RE, Tatham RL. Multivariate Data Analysis. 6th ed. Upper Saddle River: Pearson Prentice Hall; 2006.

22. Kim OS. Knowledge and compliance with prevention of respiratory tract infection among workers in geriatric facilities. Korean J Nosocomial Infect Control. 2015;20(2):61-69. doi:10.14192/kjnic.2015.20.2.61

23. Kim OS. Convergence study on the influence of vaccination encouragement and perception of influenza preventability on influenza vaccination practice among university students. J Converg Inf Technol. 2019;9(8):74-82. doi:10.22156/CS4SMB.2019.9.8.074

24. Kim OS, Hwang JW, Oh JH. 노인의 호흡기감염 예방 지식과 실천 에 관한 연구 [A study on the knowledge and practice of respiratory infection prevention in the elderly]. J Korean Soc Wellness. 2019;14 (3):135-144. doi:10.21097/ksw.2019.08.14.3.135 Korean.

25. West SG, Finch JF, Curran PJ. Structural Equation Models with Nonnormal Variables: Problems and Remedies. 1st ed. Thousand Oaks: Sage publications; 1995.

26. Tabachnick BG, Fidell LS, Ullman JB. Using Multivariate Statistics. 1st ed. Boston: Pearson; 2007.

27. Kaiser HF. An index of factorial simplicity. Psychometrika. 1974;39 (1):31-36. doi:10.1007/BF02291575

28. Woo JP. The Concept and Understanding of Structural Equation Model. 1st ed. Seoul: Hannarae Academy; 2012.

29. Kim JS, Cho HC, Kang HS. Effects of a 12-weeks walking exercise and nutrition education on adiponectin and inflammatory cytokine in obese juveniles. Exerc Sci. 2009;18(3):381-390. doi:10.15857/ ksep.2009.18.3.381
30. Jang TY, Chang BW. Meta-analysis of the influence of then elderly regular exercise on their immunity. J Digit Converg. 2017;15 (5):339-344. doi:10.14400/JDC.2017.15.5.339

31. Cho JY. The effects of aerobic exercise on immune responses by temperature environment and water intake. Korean J Converg Sci. 2019;8(3):223-234. doi:10.24826/KSCS.8.3.15

32. Jang $\mathrm{CH}$. How far has the war on infectious diseases come? Future Horizon. 2020;44:4-9.

33. Hong SH. The criteria for selecting appropriate fit indices in structural equation modeling and their rationales. Korean J Clin Psychol. 2000;19(1):161-177.

34. Grove SK, Burns N, Gray J. The Practice of Nursing Research: Appraisal, Synthesis, and Generation of Evidence. 7th ed. Amsterdam: Elsevier Health Sciences; 2012.

35. Lee EO, Im NY, Park HA, Lee IS, Kim JI, Bae JE. Nursing Study and Statistical Analysis. 1st ed. Paju: Sumoonsa; 2009.

36. Koh KW. Physical activity guideline for social distancing during COVID-19. Korean J. Health Edu Promot. 2020;37(1):109-112. doi:10.14367/kjhep.2020.37.1.109

37. Oh HS. Systemic review of social contacts of person to person spread of infections. J Korea Acad Industr Coop Soc. 2020;21(2):85-93. doi:10.5762/KAIS.2020.21.2.85

38. Shin ES. 대학생들의 건강증진행위 관련요인: 대전·충남을 중심 으로 [Factors related to health promotion behavior of some college students: focusing on Daejeon and Chungnam]. Health Welfare. 2020;22(1):199-219. doi:10.23948/kshw.2020.03.22.1.199

39. Han YM. Cooperation of the Catholic church in implementing government prevention measures against coronavirus disease (COVID-19): balance between right to religious freedom and right to health. Law Rev. 2020;20:31-61.
Journal of Multidisciplinary Healthcare

\section{Publish your work in this journal}

The Journal of Multidisciplinary Healthcare is an international, peerreviewed open-access journal that aims to represent and publish research in healthcare areas delivered by practitioners of different disciplines. This includes studies and reviews conducted by multidisciplinary teams as well as research which evaluates the results or conduct of such teams or healthcare processes in general. The journal

\section{Dovepress}

covers a very wide range of areas and welcomes submissions from practitioners at all levels, from all over the world. The manuscript management system is completely online and includes a very quick and fair peer-review system. Visit http://www.dovepress.com/testimonials. php to read real quotes from published authors. 